\title{
Resilience as a moderator between objective and subjective burden among parents of children with ADHD
}

\author{
Margherita Fossati ${ }^{1}$, Luca Negri ${ }^{1}$, Andrea Fianco ${ }^{1}$, Mario Giuseppe Cocchi ${ }^{1}$, Massimo Molteni ${ }^{1}$, Antonella Delle \\ Fave $^{1,2}$ \\ ${ }^{1}$ Scientific Institute, IRCCS E. Medea, Bosisio Parini, Lecco, Italy \\ ${ }^{2}$ Department of Pathophysiology and Transplantation, University of Milano, Milano, Italy
}

\begin{abstract}
The caring related challenges reported by parents of children with Attention Deficit and Hyperactivity Disorder (ADHD) were widely investigated. Little information is instead available on the resources mobilized by these parents in facing caring burden. In the attempt to fill this gap, the present study aimed at exploring the moderating role of resilience in the relationship between the amount of time parents of children with ADHD devote to caring tasks (objective burden) and their emotional and social burden (subjective burden). A multidimensional model of resilience was adopted, comprising six components: Self-Perception, Planned Future, Structured Style, Social Competence, Family Cohesion, and Social Resources. Participants were 44 parents (81.8\% females, aged 31-53) of children with ADHD (86.4\% males, aged 6-14). They completed the Caregiver Burden Inventory, the Resilience Scale for Adults, and the 36-Item Short Form Health Survey. Hierarchical regressions were performed to test the moderating role of resilience as a global construct, and of each resilience dimension separately, on the relation between objective and subjective burden; participants' gender and mental health scores were employed as control variables. Total resilience, Family Cohesion and Self-Perception emerged as protective factors, weakening the relationship between subjective and objective burden. Findings suggest that the potential of individual and family resources in promoting parents' adjustment to caring burden could be more effectively exploited in clinical interventions addressed to parents of children with ADHD. Overall, the identification of caregivers' strengths and resources could help practitioners to better support children with ADHD and their families.
\end{abstract}

Keywords Attention Deficit and Hyperactivity Disorder; Caregiving burden; Resilience 


\section{Introduction}

Attention-Deficit Hyperactivity Disorder (ADHD) is a neurodevelopmental disorder characterized by inattention, hyperactivity and impulsivity. In childhood ADHD has an estimated prevalence rate of 5-7\% (American Psychiatric Association, 2013; Polanczyk, de Lima, Horta, Biederman, \& Rohde, 2007; Willcutt, 2012; Thomas, Sanders, Doust, Beller, \& Glasziou, 2015); during the transition to adolescence a significant reduction of clinical manifestations is usually observed. Males are more often involved, with a gender ratio of 2:1 in clinical samples and 4:1 in population samples (American Psychiatric Association, 2013; Faraone et. al, 2015).

The consequences of ADHD manifestations on the daily lives of children and their families have been extensively described (Harpin, 2005; Wehmeier, Schacht, \& Barkley, 2010; Weiss, 2015; Faraone et. al, 2015). Impulsivity and inattention to social cues can lead children to experience rejection by peers, whereas difficulties in tasks requiring sustained attention often undermine their academic performance (Arnold, Hodgkins, Kahle, Madhoo, \& Kewley, 2015; Daley \& Birchwood, 2010; Faraone et al., 1993; Pastura, Mattos, \& Araújo, 2009) and negatively affect their self-esteem (Edbom, Granlund, Lichtenstein, \& Larsson, 2008; Mazzone et al., 2013). As concerns daily interactions, children with ADHD tend to disregard parents' ordinary requests and advice, fight with siblings and peers, disturb people in public spaces, and have difficulties in the relationship with teachers. In order to adequately manage all these daily problems, they require more attention and assistance from parents than their typically-developing peers. As a consequence, parents of children with ADHD have to invest a remarkable amount of resources in supporting their children's performance of daily tasks and pursuit of developmental goals.

\section{ADHD: a challenge for parents}

The relevant amount of time and energies that parents must invest in caring practices, in order to deal with the behavioral complexity and emotional lability of their children with ADHD, has negative implications for both their daily planning and mental health. Parents face difficulties in combining family and work responsibilities (Sellmaier, Leo, Brennan, Kendall, \& Houck, 2016), they have little time to devote to leisure and personal interests (Harpin, 2005; Neff, 2010) and their attempts to promote children's socialization often fail, resulting in withdrawal from social and public activities (Walerius, Fogleman \& Rosen, 2016). Compared to parents of typically developing children, parents of children with ADHD report worse marital relationships (Befera \& Barkley, 1985; Murphy \& Barkley, 1996; Shelton et al., 1998), lower levels of perceived family support (Shur-Fen Gau, 2007), lower parenting self-esteem (Mash \& Johnston, 1983), lower expectancies for success in managing their children's behavior (Sobol, Ashbourne, Earn, \& Cunningham, 1989) and lower parental self-efficacy (Primack et al. 2012; Rogers, Wiener, Marton, \& Tannock, 2009).

As concerns mental health, parents of children with ADHD report more psychological disorders then parents of children without ADHD, in particular depression, anxiety and alcohol abuse (Cheung \& Theule, 2016; Durukan, Kara, Almbaideen, Karaman, \& Gül, 2018; Faraone \& Biederman, 1997; Margari, et al., 2013) and higher levels of stress than parents of children with learning disabilities or with typical development (Baker \& McCal, 1995; Fisher, 1990). Prominent stress related factors include child symptoms' severity and behavioral disturbance, major and minor life events, as well as parents' psychological characteristics (such as perceived parental control over child behaviors and self-esteem), and parental psychological disorders ( Fischer, 1990; Harrison \& Sofronoff, 2002; Mash \& Johnston, 1983; Theule, Wiener, Tannock, Jenkins, 2013; Vitanza \& Guarnaccia, 1999). ADHD itself may co-occur in both parents and children (Biederman, et al. 1995; Faraone, Biederman, \& Milberger, 1994), leading to further impairments in parental functioning and higher parenting stress (Johnston \& Mash, 2001; Theule, Wiener, Rogers \& Marton, 2011). Overall, these findings suggest that the high demands involved in caring for children with ADHD, as well as personal strains contribute to undermine the positive adjustment of parents.

The problematic aspects associated with raising a child with ADHD were globally investigated in terms of caregiving burden, a multidimensional construct including objective components (e.g. daily time investment in parenting) and subjective ones (e.g. fatigue, negative emotions and perceived lack of socialization opportunities) (Caserta, Lund, \& Scott, 1996). Among the measures available to assess burden globally and in the major life domains, the Zarit Burden Interview (ZBI; Zarit, Reever, \& Bach-Peterson, 1980) is widely used in ADHD research.

A large study conducted in ten European countries among caregivers of children and adolescents diagnosed with ADHD showed the negative implications of burden in a variety of daily domains; more specifically caring burden, measured through a survey developed by the authors using concept elicitation methods, was related to missed/altered work opportunities, avoidance of social activities, increased parental worry/stress, and family life strain in spite of children's pharmacological treatment (Fridman et al., 2017). Another study conducted in Oman through the Arabic version of ZBI highlighted that parents' gender, family 
income, number of siblings, and severity/subtypes of ADHD were significantly related to burden levels ( $\mathrm{Al}$ Balushi, Al Shukaili, \& Al Adawi, 2017). High levels of burden, assessed through the ZBI, were also detected among caregivers of children and adolescents with ADHD living in Nigeria (Adeosun, Ogun, Adegbohun, Ijarogbe \& Fatiregun, 2017). Data collected in the UK among parents of adolescents and young adults, using a brief version of ZBI (Cadman et al., 2012), highlighted that burden was specifically associated with the perception of children's unmet needs at the emotional and relational levels.

Overall, the relevant role of caring burden identified across studies calls for a deeper investigation of this phenomenon, in order to clarify the unique contribution of both the objective and subjective components of burden, their mutual relationship, and the role of other sociodemographic variables in the experience of parents raising children with ADHD.

\section{Parents' well-being and resilience: recent topics in disability research}

During the last two decades, researchers' focus on the strain and stress associated with the caring role was progressively expanded towards including caregivers' well-being, personal resources and social support. This broadening in focus characterized research on ADHD as well.

Across disease conditions, at the individual level successful adjustment to the caregiving role was associated with high positive and low negative affect (Robertson, Zarit, Duncan, Rovine, \& Femia, 2007; Song, et al., 2014), adaptive coping strategies (Bauer, Koepke, Sterzinger, \& Spiessl, 2012), internal locus of control (Lloyd \& Hastings, 2009), and high sense of coherence (Oelofsen \& Richardson, 2006). At the relational level, adaptive management of care-recipient needs was associated with perceived support and cohesion within the family and in the social context (Delle Fave, Fianco, \& Sartori, 2015; Motl, McAuley, Snook, \& Gliottoni, 2009; Rolland \& Walsh, 2006).

As specifically concerns ADHD research, the traditional assessment of parental well-being as absence of psychological distress and negative emotions was integrated by the investigation of positive indicators of mental health (Neff, 2008; 2010). Studies were conducted to assess stress-related personal growth (ModestoLowe, Chaplin, Godsay, \& Soovajian, 2014; Finzi-Dottan, Triwitz \& Golubchik, 2011) and positive parenting (Ellingsen, Baker, Blacher, \& Crnic, 2014), as well as their predictors. Parents' adoption of adaptive coping strategies, such as problem appraisal and problem management, was associated with better quality of life, greater sense of control and higher personal fulfillment, while perceiving the child's condition as a threat or a loss and adopting emotion-focused coping strategies predicted poorer quality of life (Cappe, Bolduc, Rouge, Saiag, \& Delorme, 2017).

Adaptive responses and positive adjustment to adversarial life conditions are often investigated within the framework of resilience (Luthar, Chicchetti, \& Becker, 2000; Masten \& Wright, 2009), defined as a global regulatory capacity to effectively manage stressful situations (Masten \& Obradovic, 2007) through the mobilization of personal and social resources, that include psychological assets and potentials, family cohesion and value sharing, and social support (Di Corcia \& Tronick, 2011). Resilience was operationalized through different empirical models (Zautra et al., 2012) in studies involving parents of children with physical and mental disabilities. Resilience facets were identified among primary caregivers of children and adolescents with autism (Bayat, 2007), among mothers of children and adults with disabilities (Lee, Park, \& Recchia, 2015), and in couples of parents of young children with severe disability (Graungaard, Andersen, \& Skov, 2011). Resilience processes and trajectories were detected and analyzed among families of 3-year-old children with intellectual disabilities (Gerstein, Crnic, Blacher, \& Baker, 2009); results highlighted the relevance of individual parent characteristics, quality of dyadic relationships and inter-parental influences in the adjustment to child disability. A systematic review of studies conducted among parents of children with intellectual and/or developmental disabilities (Peer \& Hillman, 2014) identified coping style, optimism, and social support as main resilience factors. Parental resilience was positively associated with well-being indicators such as self-reported health (Ruiz-Robledillo, De Andres-Garcia, Perez-Blasco, Gonzalez-Bono, \& Moya-Albiol, 2014), and quality of life (Migerode, Maes, Buysse, \& Brondeel, 2012).

The relationship between resilience and caregiving burden was predominantly investigated among caregivers of adults. Significantly negative correlations between burden and resilience were detected among caregivers of older persons with dementia (Gönen Şentürk, Akyol, \& Küçükgüçlü, 2018) and of adults with spinal cord injury (Vagharseyyedin \& Molazem, 2013). In a study conducted among parents of persons with autism spectrum disorders (Bekhet, Johnson, \& Zauszniewski, 2012), positive cognitions were identified as mediators between caregiving burden and resourcefulness (considered as an indicator of resilience). In a group of caregivers of older adults, the relationship between burden and resilience was mediated by perceived social support (Ong et al., 2018). Finally, a study involving parents of persons (aged 5-53), diagnosed with cognitive and neuromotor disorders, investigated resilience and life satisfaction (well-being indicators) and depression related emotions (an ill-being indicator) as predictors of caregivers' subjective burden (Fianco et al., 2015); life 
satisfaction and resilience emerged as significant predictors of burden; after accounting for their contributions, depression related emotions did not show any significant association with caregivers' subjective burden levels.

Overall, these findings suggest that psychological resources and positive mental health indicators, such as resilience, could be usefully included in intervention programs, by virtue of their role as protective factors against burden perception. This research avenue seems to be promising for applications in the context of childhood disabilities (and particularly ADHD); a thorough literature search, however, did not yield any results.

\section{Study aims}

Despite the growing body of research addressing stress, burden and well-being indicators among parents of children with ADHD, to the best of our knowledge no studies have been conducted yet to investigate parental resilience and its role in buffering caregiving burden and stress. The present study was therefore aimed at investigating the role played by resilience in the relationship between objective burden (the amount of time devoted to care activities) and subjective burden (perceived social, emotional and psychophysical burden) among parents of children with ADHD. To the purpose of this study, resilience was conceptualized and operationalized following Friborg and colleagues (Friborg, Hjemdal, Rosenvinge \& Martinussen, 2003; Werner, 2000), who developed a comprehensive model comprising six dimensions: four of them refer to individual positive characteristics, one to family support and cohesion, and one to social supportive networks (Hjemdal, 2007). Individual characteristics include self-perception (confidence in one's own abilities, self-efficacy, positive outlook toward oneself), planned future (positive outlook toward one's own future, ability to formulate and pursue clear goals), social competence (flexibility in social interactions, ability to build new relations), and structured style (being able to organize daily time and activities). The dimension family cohesion refers to shared values, amount of family conflict, cooperation, support, loyalty and stability within the family. Social resources include quality of support perceived from social networks and significant others outside the family, as well as appreciation from others.

In statistical terms, resilience was analyzed as a moderator of the relationship between the two components of burden. On this basis, a general hypothesis was formulated:

$H_{1}$ : Resilience would moderate the relationship between objective and subjective burden, so that high levels of resilience have a significant effect on burden perception compared to low levels of resilience. More specifically, higher resilience levels are expected to reduce the magnitude of the bivariate relation between the two dimensions (buffering effect).

In the case of $H_{l}$ confirmation, the following additional hypotheses were formulated, in order to more specifically verify the moderating role of each of the six dimensions of resilience in the relationship between objective and subjective components of burden:
$\mathrm{H}_{2}$ : Family Cohesion;
$\mathrm{H}_{3}$ : Social Resources;
$\mathrm{H}_{4}$ : Self Perception;
$\mathrm{H}_{5}$ : Social Competence;
$\mathrm{H}_{6}$ : Planned Future;
$\mathrm{H}_{7}$ : Structured Style.

\section{Method}

\section{Procedure and participants}

A cross-sectional design was adopted for this study, conducted in collaboration with two child neuropsychiatric units in Northern Italy: IRCCS E. Medea - La Nostra Famiglia in Bosisio Parini and Manzoni Hospital in Lecco. After approval by the Ethics Committees of the two institutions, clinicians identified families matching the research inclusion criteria: eligible participants were parents of children with ADHD (either HyperactiveImpulsive, Inattentive, or Combined subtype), never enrolled in Parent Training programs. A researcher contacted eligible participants either by phone or in person, informing them about the main project aims. A total of 45 parents agreed to take part in the study. They were invited to a meeting at the unit, in which they filled out an informed consent form and were provided with a set of questionnaires. In each family, the parent most involved in child daily care was selected for participation in the study.

Participants could complete the questionnaires immediately or at home, returning them to the researcher within two weeks. In both cases, they were offered a debriefing session in which they could express personal comments and doubts, and receive further information on the study aims. Anonymity was guaranteed in all research phases. 


\section{Research instruments}

Participants filled out the following scales:

Caregiver Burden Inventory (CBI, Novak \& Guest,1989; Italian version Marvardi et al., 2005). It comprises 24 items on 0-4 Likert-type scales, grouped into five dimensions: Objective Burden (OB; time devoted to the care activities, 5 items), developmental burden ( 5 items), physical burden (4 items), social burden ( 5 items) and emotional burden ( 5 items). Scores for each dimension are obtained by summing up the respective item values; the sum of developmental, physical, social and emotional burden scores is globally interpreted as Subjective Burden (SB); a total burden score can also be calculated as the sum of OB and SB (values range 096). The CBI validity, well documented in caregivers of adults, has been recently supported in caregivers of children with Pediatric Acute-onset Neuropsychiatric Syndrome (Farmer et al. 2018); the CBI was employed with parents of children with Autism Spectrum Disorders (Ji, Sun, Yi, \& Tang, 2014) and adapted for use with parents of children with Rett Syndrome (Lane et al., 2017).

Resilience Scale for Adults (RSA; Friborg et al., 2003, Italian version: Peveri, 2010). RSA investigates positive adaptation to aversive conditions through 33 items based on 1-5 semantic differential-type response format. The instrument is consistent with the six factor model of resilience proposed by Friborg et al. (2003) and Hjemdal (2007); items are thus grouped in the following dimensions: Family Cohesion (FC), Social Resources (SR), Self Perception (SP), Planned Future (PF), Social Competence (SC), and Structured Style (SS). The total resilience score is obtained by summing the item values of each dimension (range 33-165). Higher scores indicate higher levels of resilience. More specifically, low resilience levels correspond to values below 77, moderate levels to values in the 78-121 range, and high levels to values above 122.

36-Item Short Form Health Survey (SF-36; Ware \& Sherbourne, 1992; Italian version: Apolone, Cifani, Liberati, \& Mosconi, 1997). The instrument assesses perceived health and well-being in eight different areas: Vitality, Physical Functioning, Bodily Pain, General Health, Role Limitations due to Physical Health Problems, Role Limitations due to Emotional Problems, Social Functioning and Mental Health. Items' weighted sums are calculated for each area, and transformed into 0-100 scales. Higher scores correspond to higher levels of perceived health in that area. For the purposes of this study only the Mental Health (MH) subscale was included in the analyses; $\mathrm{MH}$ is assessed trough 5 items on a 1-6 Likert-type format.

\section{Data analysis}

As a first step, data were inspected to detect missing values in scaled answers. Cronbach's alpha reliability indices were calculated for each instrument; only dimensions with $\alpha$ values $>.69$ were retained for further analyses.

Descriptive statistics and correlation coefficients were calculated for demographic features and study measures. In line with the literature, associations were interpreted as meaningful with coefficient values >.30. Above this threshold, values lower than .50 were interpreted as indices of low correlation, between .50 and .70 as indices of moderate correlation, and above .70 as indices of high correlation between variables (Hinkle, Wiersma \& Jurs, 2003).

In order to test $H_{1}$, a hierarchical regression analysis using Ordinary Least Square (OLS) estimation technique was employed. Subjective Burden was considered as a criterion variable, while Objective Burden and Total Resilience (TR) were treated as predictor and moderator respectively. All measures showing a correlation value $>|.30|$ with SB (criterion variable) were inserted as control variables in Step 1. In order to reduce multicollinearity (Aiken \& West, 1991), OB (the predictor) and TR (the moderator) were centered at their mean values and inserted in Step 1 as well. The interaction term (centered OB X centered TR) followed in Step 2. All variables in the model were inspected for assumption of OLS multivariate regression to be met. In presence of a significant interaction, a post-hoc simple slope analysis was employed to clarify the role of Total Resilience (the moderator) in the relationship between Objective Burden (the predictor) and Subjective Burden (the criterion variable).

\section{Results}

\section{Preliminary analyses Participants}

One participant was excluded from analyses due to a percentage of missing answers in the RSA scale $(15 \%)$ beyond acceptability threshold. No missing values were found in the other participants' questionnaires. The analyses were thus conducted on 44 participants, 81.8\% mothers, aged 31-53 (M=41.05; SD=5.38). Most caregivers $(75 \%)$ had a paid job; as regards education, $56.8 \%$ had a high school diploma, $27.3 \%$ a middle school one, and $15.9 \%$ a college degree. The majority (63.6\%) had two children, $13.6 \%$ had one child, $15.9 \%$ three children, $2.3 \%$ four children and $4.5 \%$ five children. Children with ADHD were predominantly males (86.4\%), aged 6-14 ( $\mathrm{M}=9.86 ; \mathrm{SD}=2.29)$. 


\section{Descriptive statistics}

Instruments' reliability values are reported in Table 1, along with descriptive statistics of all study measures and correlation indices. Two resilience subscales (Planned Future and Structured Style) did not meet the $\alpha$ requirement for acceptability and were thus excluded from subsequent analyses.

\section{TABLE 1 about here}

Participants' Mental Health scores did not significantly differ from the Italian normative data ${ }^{1}$ at a $t$-test comparison. The Total Resilience mean score was comprised in the high resilience range; in addition, no participant reported values in the low resilience range. In order to detect the prominence of Objective vs. Subjective Burden, total OB and SB scores were first divided by the number of related items, and a $t$-test for dependent samples was then performed. Subjective Burden showed significant lower values than Objective Burden $\left(\mathrm{M}_{\mathrm{OB}}=1.16, \mathrm{SD}_{\mathrm{OB}}=0.67 ; \mathrm{M}_{\mathrm{SB}}=0.54, \mathrm{SD}_{\mathrm{SB}}=0.47 ; \mathrm{t}(43)=7.80 ; p<.001\right)$.

As concerns associations among the variables, Subjective Burden showed: a moderate positive correlation with Objective Burden, a low positive correlation with participants' gender, low negative correlations with Family Cohesion, Social Resources and Self Perception, moderate negative correlations with Mental Health and Total Resilience, and no significant correlation with Social Competence. The correlations between Objective Burden and the potential moderators (Total Resilience and the four resilience subscales selected for analysis) did not hit significant values.

Participants' gender and Mental Health emerged as the sole measures showing a correlation value > $\mid .30$ with Subjective Burden, They were included as control variables in the subsequent hierarchical regression analysis.

\section{The moderating role of Total Resilience between objective and subjective burden}

In order to test $H_{1}$, a hierarchical regression with Subjective Burden as criterion was employed. Mean centered Objective Burden (predictor) and Total Resilience (moderator) were inserted in Step 1, together with control variables (participants' gender and Mental Health). The interaction term (Objective Burden x Total Resilience) was inserted in Step 2. As a preliminary step, data were inspected for violations of multivariate regression assumption. Comparison of Mahalanobis Distance values with $\chi^{2}$ probability distribution did not led to detection of multivariate outliers. Normal distribution of the error terms was checked trough the probability plot of standardized residuals and Shapiro-Wilk (W) test; both procedures excluded significant deviations from normality $(\mathrm{W}(44)=.96, p=.11)$. Homoskedasticity was confirmed by a non-significant result of Koenker alternative to the Breusch-Pagan test: $B^{\text {Koenker }}=5.12 ; p=.40$ (Koenker, 1981). All Variance Inflation Factor values (VIF) ranged from 1 to 1.25 , indicating a very low, and thus acceptable, level of multicollinearity. DurbinWatson test value (DW=2.2) suggested absence of relevant autocorrelation in residuals. Results of the hierarchical regression analysis are reported in Table 2.

\section{TABLE 2 ABOUT HERE}

The first step of the regression model was significant $(F(4,39)=29.5, p<.001)$; as expected, Objective Burden was positively related to Subjective Burden, while Total Resilience was negatively related to it. The interaction term accounted for an additional $3 \%$ of the model variance $(\mathrm{F}(1,38)=5, \mathrm{p}=.03)$, supporting the moderation hypothesis. The moderating effect of Total Resilience was inspected through a post-hoc simple slope analysis, illustrated in Figure 1. The interaction was probed by testing the conditional effects of Objective Burden at three levels of resilience: one standard deviation below the mean; at the mean, and one standard deviation above the mean. Objective Burden was significantly related to Subjective Burden when resilience was both below the mean $(B=1.7, t=6.84, p<.001)$ and at the mean $(B=1.21, t=5.36, p<.001)$, but not when it was above the mean $(\mathrm{B}=0.71, \mathrm{t}=1.90, \mathrm{p}=.06)$. These results supported $\mathrm{H} 1$, as a buffering effect of resilience on the bivariate relationship between objective and subjective components of burden was identified.

\section{FIGURE 1 ABOUT HERE}

The Johnson-Neyman technique (Bauer \& Curran, 2005) showed that the relationship between Objective and Subjective Burden was significant when resilience was lower than .94 standard deviations above the mean score. For higher resilience values, reported by $22.7 \%$ of the participants, this relationship was not significant. No gender differences emerged among participants reporting values higher or lower than this threshold $(p=.35$, Fisher's exact test).

\footnotetext{
${ }^{1}$ Detailed results are available from the corresponding author upon request
} 


\section{Resilience dimensions as moderators between objective and subjective burden}

Since $H_{1}$ was confirmed, the same procedure was adopted in order to identify the specific role played by each resilience dimension in moderating the relationship between objective and subjective components of burden. Based on the reliability values reported in Table 1, only hypotheses referring to Family Cohesion $\left(\mathrm{H}_{2}\right)$; Social Resources $\left(H_{3}\right)$; Self Perception $\left(H_{4}\right)$ and Social Competence $\left(H_{5}\right)$ were tested.

Therefore, four separate hierarchical regressions were performed, with Subjective Burden as criterion. Participants' gender and Mental Health were retained as control variables and inserted in Step 1 of each regression, together with Objective Burden (predictor) and, separately, the moderators. The associated interaction term followed in Step 2 of each regression. Violations of OLS requirements ${ }^{2}$ were detected for the models including Family Cohesion and Social Competence. In both cases, one participant was identified as a multivariate outlier and thus excluded from the subsequent analysis. As a result, the regression models with these two dimensions as predictors included 43 participants.

Table 3 and 4 show the results of the regression analyses performed with Family Cohesion and Self Perception as predictors ( $H_{2}$ and $H_{4}$ respectively).

\section{[TABLE 3 ABOUT THERE]}

\section{[TABLE 4 ABOUT THERE]}

In both models, moderators were not found to be significantly related to Subjective Burden. However, a significant $\mathrm{R}^{2}$ change associated to Step 2, containing the interaction term derived from Family Cohesion $(F(1,37)=6.55, p=.01)$, and Self Perception $(F(1,38)=4.21, p=.047)$ respectively, supported the moderation hypothesis.

Post-hoc simple slope analyses were further employed to separately inspect the moderating effect of Family Cohesion (Figure 2) and Self Perception (Figure 3) on the relationship between Objective and Subjective Burden.

Objective Burden was significantly related to Subjective Burden when Family Cohesion was both one standard deviation below the mean $(\mathrm{B}=1.96, \mathrm{t}=5.76, p<.001)$ and at the mean $(\mathrm{B}=1.21, \mathrm{t}=4.91, p<.001)$, but not when it was one standard deviation above the mean $(\mathrm{B}=0.46, \mathrm{t}=1.1, p=.28)$, in line with the hypothesized buffering effect $\left(H_{2}\right)$.

\section{[INSERT FIGURE 2 ABOUT HERE]}

More specifically, the relationship between Objective and Subjective Burden was significant for values of Family Cohesion lower than .68 standard deviations above the mean. Out of 43 participants, $34.9 \%$ reported values higher than this threshold; no gender difference was detected with participants reporting lower values ( $p=1$, Fisher's exact test).

As shown in Figure 3, Objective Burden was significantly related to Subjective Burden when Self Perception was both one standard deviation below the mean $(\mathrm{B}=1.74, \mathrm{t}=6.22, p<.001)$ and at the mean $(\mathrm{B}=1.21, \mathrm{t}=5.04, p$ $<.001)$, but not one standard deviation above the mean $(\mathrm{B}=0.69, \mathrm{t}=1.68, p=10$.), supporting the buffering effect $\left(H_{4}\right)$.

\section{[INSERT FIGURE 3 ABOUT HERE]}

More specifically. the relationship between Objective and Subjective Burden was significant for values of Self Perception lower than .85 standard deviations above the mean. Out of 44 participants, $20.5 \%$ showed values higher than this threshold; no gender difference emerged between them and participants reporting lower values $(p=.33$, Fisher's exact test).

In the models using Social Resources and Social Support as predictors, the contribution of the interaction term to the explained variance change was not significant $\left(\Delta \mathrm{R}^{2}=.011, F(1,38)=1.58, p=.25\right.$; and $\Delta \mathrm{R}^{2}=.006$, $F(1,37)=0.96, p=.33$ respectively). Therefore, $H_{3}$ and $H_{5}$ were not confirmed.

\footnotetext{
${ }^{2}$ Detailed results are available from the corresponding author upon request
} 


\section{Discussion}

The purpose of this study was to investigate the relationship between resilience and caring burden in a group of Italian parents of children with ADHD. More specifically, resilience was expected to play a moderating role in the relationship between the objective component of burden (time devoted to care activities) and the subjective one (perceived developmental, physical, social and emotional strain and limitations).

The relation between subjective and objective burden was often investigated among family caregivers; results were however contradictory and sometimes difficult to compare, as burden measures differed across studies. A negligible association between subjective and objective burden was detected in family members of persons with psychiatric disorders (Potasznik \& Nelson, 1984); a high correlation instead emerged in adult caregivers of persons with depression (Coyne et al., 1987); a moderate correlation was detected in family members of adults with Multiple Sclerosis (Bayen, Papeix, Pradat-Diehl, Lubetzki, \& Joël, 2015), and a low correlation in partners of persons with spinal cord injury (Fekete, Tough, Siegrist, \& Brinkhof, 2017).

In the present study, the first one exploring this issue among parents of children with ADHD, subjective and objective burden showed a moderately positive correlation; participants' subjective burden levels were however comparatively lower than objective burden ones. The degree of correlation between the two burden components, as well as their average values, can be interpreted taking into account the parents' double responsibility for both performing routine childrearing tasks, and dealing with the social and emotional challenges connected with the peculiar behavioral characteristics of children with ADHD. Although parenting by definition includes supporting children in daily living activities, during the performance of these tasks children with ADHD require higher attention as well as emotional and relational effort from parents, compared with their typically developing peers; across daily circumstances, parents strive to adequately manage their children's behaviors, the relationship with them and their interactions with the society. Nevertheless, the relatively low levels of the subjective component of burden compared to the objective one suggest that these participants do not experience caregiving as a substantial obstacle to their global adjustment. Demographic features that can further clarify this result comprise participants' relatively young age and related amount of psychophysical resources; the status of workers characterizing the majority of these parents, allowing them to experience a different and less emotionally demanding context during daily life; their parenting role towards other children, whose developmental progresses may represent a source of gratification and a support of their self-esteem and parental self-efficacy, counterbalancing their difficulties with the child with ADHD.

In order to better understand the relationship between the two components of burden, we investigated the role of resilience, identified as an important resource in the process of adaptation to stressful and challenging life conditions (Masten, Cutuli, Herbers \& Reed, 2009; Rutter, 1987). We primarily hypothesized that resilience could represent a moderator between objective and subjective burden in parents of children with ADHD. In addition, the multidimensional model of resilience adopted in the present study (Friborg et al., 2003) allowed us to explore the contribution of different resilience dimensions to this moderating role.

Results confirmed the primary hypothesis, showing that burden perception was related to participants' levels of Total Resilience. In particular, parents with resilience scores higher than .94 standard deviations above the mean were less likely to experience high subjective burden than parents with total scores below this threshold. For these participants resilience acted as a protective factor for subjective burden, weakening its relationship with objective burden. These results are consistent with the positive relationship between resilience and adaptability to stressors detected among adults (Friborg et al., 2006), older adults (Ong, Begerman, Bisconti \& Wallace, 2006) and caregivers of adults with dementia (Gaugler, Kane \& Newcomer, 2007) or schizophrenia (Chen, et al., 2016). In addition, they contribute with novel evidence to the scanty literature addressing these topics among caregivers of children with developmental disabilities, predominantly focused on autism (Lindsey \& Barry, 2018; Weiss et al., 2013).

The relationship of resilience with burden was further explored by testing the moderating role of each of its dimensions. Planned Future and Structured Style were discarded from analysis due to unacceptable $\alpha$ values, also detected in other studies using the same resilience assessment scale (Friborg, Barlaug, Martinussen, Rosenvinge, \& Hjemdal, 2005). A moderating role was instead detected for the dimensions of Family Cohesion and Self Perception $\left(\mathrm{H}_{2}\right.$ and $\left.\mathrm{H}_{4}\right)$, that emerged as protective factors buffering parents' subjective burden in the face of objective burden. These dimensions refer to two different domains of resilience development, the family and the individual domain respectively.

Family Cohesion is a broad dimension, encompassing the components of perceived support, shared values, absence of conflict, cooperation, and relational stability in the family. Its relevance has been highlighted in ADHD research, especially for the component of family support, analyzed as a mediator between family hardiness and global family functioning (Chen, Clark, Chang, Liu, \& Chang, 2014), or as an insufficient resource requiring implementation (Lange et al., 2005). Other components of family cohesion indirectly explored in parents of children with ADHD were marital problems (family conflict), significantly higher than in 
parents of children without ADHD (Murphy \& Barkley, 1996), and parental agreement on child rearing (referable to shared values and cooperation), showing a positive association with better marital adjustment and lower conflict levels (Harvey, 2000).

Findings from the present study contribute to the current literature by suggesting that a stable and coherent family environment, where both parents agree upon clear rules, apply them consistently over time, and provide consistent feedback (both positive and negative) to the child's behavior may represent a useful resource to effectively manage the behavioral and emotional difficulties of children with ADHD. In particular, family cohesion could be fruitfully addressed in clinical intervention programs such as Behavioral Parent Training (BPT), a treatment of choice for families of children with ADHD (Pelham, Wheeler \& Chronis, 1998; Pelham \& Fabiano, 2008; Zwi, Jones, Thorgaard, York, \& Dennis, 2009), that provides parents with behavior modification techniques aimed at increasing positive outcomes with their children (Chronis, Chacko, Fabiano, Wymbs, \& Pelham, 2004; Pelham, Wheeler, \& Chronis, 1998). Although marital dissatisfaction and interparental discord were highlighted as factors potentially interfering with the long term outcomes of BPT among parents of children with ADHD (Chronis, Chacko, Fabiano, Wymbs, \& Pelham, 2004), no explicit evidence is reported about the potential usefulness of reinforcing parental agreement and cooperation (Harvey, 2000).

Our findings finally suggest that specifically targeting family cohesion in BPT programs could also contribute to the promotion of parents' wellbeing, by virtue of its buffering role in the relationship between objective and subjective burden. Further research is however needed to better disentangle the role of family cohesion, as its relational nature calls for studies involving both parents or all the family members, whereas data referring to parental practices or parent-child relationships are primarily derived from only one parent, or from each parent separately (Johnston \& Mash, 2001; Deault, 2010). A laudable exception is represented by a study (Harvey, 2000) evaluating mother's and father's similarities in parenting values, beliefs, and practices, and showing their positive relation with better marital adjustment, lower marital conflict and fewer comorbid disruptive behaviors in children.

Caution is instead needed in interpreting the study results concerning the resilience dimension of Self Perception, whose moderating role between subjective and objective burden was only marginally significant. A vast literature is available on the association between parents' positive self-evaluation (assessed in terms of perceived abilities and competences, in general or in relation to parenting) and their successful management of parenting tasks and difficulties. Several studies explored the positive role of parental self-efficacy in promoting parent and child adjustment was detected in both clinical and non-clinical populations (see Jones \& Prinz, 2005, for a review). In the context of ADHD research, perceived self-efficacy in parenting practices (Ardelt \& Eccles, 2001; Bandura, 1997) was associated with higher expectations about the effectiveness of behavioral strategies suggested by clinicians to manage child conducts (Johnston, Mah, \& Regambal, 2010; Jiang, Gurm, \& Johnston, 2014). In the same vein, low parenting efficacy in fathers and low self-esteem in mothers were associated with worse child treatment outcome (Hoza et al., 2000). Overall, these findings suggest the usefulness of promoting parents' self-efficacy through a careful evaluation of the congruence between objective abilities and perception of possessing them (Bandura, 1997). In the context of this literature, the only marginal buffering role played by Self-Perception against burden in our study could be related to the still limited knowledge and awareness of the participants - not yet enrolled in Parent Training programs - about the resources they could mobilize to more effectively manage their child's problems. Longitudinal studies could better elucidate this aspect, by exploring variations in the moderating role of Self Perception between objective and subjective burden over time, taking into account child treatment evolution and parents' exposure to training programs.

Differently from our expectations, the two resilience dimensions of Social Competence and Social Resources did not moderate the relationship between objective and subjective burden. These dimensions reflect different aspects of the person's interaction with the social context. Social Competence refers to the individual's flexibility in social interactions and disposition toward social relations; Social Resources instead refers to the perception of support from other persons or social networks outside the family. Previous studies with caregivers (including parents of children with ADHD) highlighted a significantly negative association between social support and distress (Lindsey \& Barry, 2018; Theule et al., 2011); the specific role of social support as a moderator between objective and subjective burden was however not investigated yet. Nevertheless, research evidence attests to the difficulties faced by families of children with ADHD in the interaction with their social environment, including stigma and discredit of their parental competences due to their children's inability to fit into social norms (Mueller, Fuermaier, Koerts, \& Tucha, 2012), leading to a relative isolation of these families within the social context. These findings contribute to explain the irrelevance of the social dimensions of resilience in moderating the relationship between burden components, detected in our study. Due to the remarkable consequences of this situation for families' well-being and social integration, additional research efforts are required to better understand the relationship between perceived social resources, social competence and self-perception among families of children with ADHD. Related findings could also help verify the 
moderating role of self-perception in the relationship between objective and subjective burden, vis-à-vis the absence of such role for social support, and clarify the underlying mechanisms.

In the present study, parents' gender and mental health level were taken into account as control variables, based on their significant correlations with subjective burden. Gender showed a low association with Subjective Burden, with mothers reporting higher values than fathers. This result is consistent with other studies involving parents of children with autism spectrum disorders (Picardi et al., 2018), even though it should be interpreted with caution, due to the low percentage of fathers included in our sample (18.2\%). It is however worth noting that worldwide women represent the vast majority of caregiving parents, for children with ADHD (e.g. Theule et al., 2011) and other disabilities (Negri, Piazza, Sartori, Cocchi, \& Delle Fave, 2018). With regard to Mental Health, in line with other studies (Bayen, et al., 2015; Fekete, et al., 2017), it was negatively correlated with Subjective Burden, and not significantly associated with Objective Burden. Participants did not differ from the Italian normative sample in mental health levels, in line with studies suggesting that, in spite of increased stress levels, the risk of developing poor mental health in families of children with disabilities may not be as high as expected (Emerson, et al., 2010; Montes \& Halterman, 2007).

\section{Strengths, limitations, and future directions}

Taken together, findings from the present study underscore the role of both individual and family resources in parents' adjustment to the burden of caring for a child with ADHD. To the best of our knowledge, no study had previously investigated subjective and objective burden separately, as well as in conjunction with resilience, in this specific population. Although the lack of previous evidence prevents from drawing comparisons, these results can pave the way to future research on this specific topic. Overall, the findings suggest the usefulness of complementing research on parental stress and difficulties with the investigation of individual and family resources and protective factors, that can promote caregivers' wellbeing and family adjustment. At the clinical level, these dimensions can be implemented both as protective factors in prevention programs, and as resources contributing to the effectiveness of parent training protocols, beyond child symptom control (Heath, Curtis, Fan \& McPherson, 2015; Tarver, Daley, \& Sayal, 2015).

Despite its innovative aspects, this study has several limitations. The sample size was small and imbalanced as concerns gender. Participants and their children attended two Italian rehabilitation institutions representing positive models of integrated care. Therefore, results cannot be generalized and further investigation is required, involving users of different typologies of healthcare services. Another study limitation concerns the age of participants' children, all attending primary or secondary school. As age related changes in ADHD clinical manifestations pose specific challenges to caregivers (Cadman et al. 2012; DuPaul, McGoey, Eckert, \& VanBrakle, 2001; Harpin, 2005), it would be important to investigate caregiving burden and its relation with resilience in parents of younger and older children. Finally, the cross-sectional study design does not provide evidence of directionality and causality between the examined variables. Longitudinal studies with larger samples are needed to this purpose.

As concerns future research directions, the investigation of the relationship between child and family features, dimensions of caregiver burden, and dimensions of resilience could provide useful suggestions to practitioners, helping them broaden and strengthen the support offered to children with ADHD and their families. The promotion of caregivers' awareness and mobilization of individual and family resources could represent a useful implementation of parent training programs, allowing families to more effectively manage ADHD related challenges.

Funding: This work was financially supported by Italian Ministry of Health (Ricerca Corrente 017/14).

\section{References}

Adeosun, I.I., Ogun, O., Adegbohun, A., Ijarogbe, G., \& Fatiregun, O. (2017). The Burden on Caregivers of Children with Attention-deficit Hyperactivity Disorder in Lagos Nigeria: Prevalence and Correlates. Journal of Education, Society and Behavioural Science, 22(1), 1-7.

Aiken, L. S., \& West, S. G. (1991). Multiple regression: Testing and interpreting interactions. Newbury Park: Sage.

Al Balushi, N., Al Shukaili, M., Al Adawi, S. (2017). Burden for caregivers of children with attentiondeficit/hyperactivity disorder in Oman. European Psychiatry,41, S120-S121.

American Psychiatric Association (2013). Diagnostic and Statistical Manual of Mental Disorders, Fifth Edition (DSM-5). Washington, D.C.: APA. 
Apolone, G., Cifani, S., Liberati, M. C., \& Mosconi, P. (1997). Questionario sullo stato di salute SF-36. Traduzione e validazione della versione italiana: risultati del progetto IQOLA. [36-Item Short Form Health Survey - SF-36. Italian translation and validation: results of the IQOLA project] Metodologia e Didattica Clinica, 5, 86-94.

Ardelt, M., \& Eccles, J. S. (2001). Effects of mothers' parental efficacy beliefs and promotive parenting strategies on inner-city youth. Journal of Family Issues, 22, 944-972.

Arnold, L. E., Hodgkins, P., Kahle, J., Madhoo, M., \& Kewley, G. (2015). Long-Term Outcomes of ADHD: Academic Achievement and Performance. Journal of Attention Disorders. E-pub ahead of print, doi: $10.1177 / 1087054714566076$.

Baker, D. B., \& McCal, K. (1995). Parenting stress in parents of children with attention-deficit hyperactivity disorder and parents of children with learning disabilities. Journal of Child and Family Studies,4, 57-68.

Bandura, A. (1997). Self-efficacy: The exercise of control. New York: W H Freeman/Times Books/ Henry Holt \& Co.

Bauer, D. J., \& Curran, P. J. (2005). Probing interactions in fixed and multilevel regression: Inferential and graphical techniques. Multivariate Behavioral Research, 40(3), 373-400.

Bauer, R., Koepke, F., Sterzinger, L., \& Spiessl, H. (2012). Burden, rewards, and coping - the ups and downs of caregivers of people with mental illness. The Journal of Nervous and Mental Disease, 200, 928-934.

Bayat, M. (2007). Evidence of resilience in families of children with autism. Journal of Intellectual Disability Research 51,702-714.

Bayen, E., Papeix, C., Pradat-Diehl, P., Lubetzki, C., \& Joël, M. E. (2015). Patterns of objective and subjective burden of informal caregivers in Multiple Sclerosis. Behavioural Neurology, 1-10.

Befera, M. S., \& Barkley, R. A. (1985). Hyperactive and normal girls and boys: Mother-child interaction, parent psychiatric status and child psychopathology. Journal of Child Psychology and Psychiatry, 26, 439-542.

Bekhet, Abir \& Johnson, Norah \& Zauszniewski, Jaclene. (2012). Effects on Resilience of Caregivers of Persons With Autism Spectrum Disorder: The Role of Positive Cognitions. Journal of the American Psychiatric Nurses Association. 18 (6).

Biederman, J., Faraone, S. V., Mick, E., Spencer, T., Wilens, T., Kiely, K., . . Warburton, R. (1995). High risk for attention deficit hyperactivity disorder among children of parents with childhood onset of the disorder: A pilot study. The American Journal of Psychiatry, 152(3), 431-435.

Cadman, T., Eklund, H., Howley, D., Hayward, H., Clarke, H., Findon, J., ... Glaser, K. (2012). Caregiver burden as people with ASD and ADHD transition into adolescence and adulthood in the United Kingdom. Journal of the American Academy of Child and Adolescent Psychiatry, 51, 879-888.

Cappe, E., Bolduc, M., Rouge, M.,Saiag, M., \& Delorme, R. (2017). Quality of life, psychological characteristics, and adjustment in parents of children with Attention-deficit/Hyperactivity Disorder. Quality of Life Research, 26, 1283-1294.

Caserta, M. S., Lund, D. A., \& Scott, D. V.(1996). Exploring the Caregiving Burden Inventory (CBI). Further evidence for a multidimensional view of burden. Journal of Aging and Human Development,43, 21-34.

Chen, J.Y., Clark, M.J., Chang, Y.Y., Liu, Y.Y., \& Chang, C.Y. (2014). Factors affecting perceptions of family function in caregivers of children with Attention Deficit Hyperactivity Disorders. Journal of Nursing Research, 22(3), 165-175.

Chen, X., Mao, Y., Kong, L., Li, G., Xin, M., Lou, F., \& Li, P. (2016). Resilience moderates the association between stigma and psychological distress among family caregivers of patients with schizophrenia. Personality and Individual Differences, 96, 78-82.

Cheung, K., \& Theule, J. (2016). Parental psychopathology in families of children with ADHD: A metaanalysis. Journal of Child and Family Studies, 25(12), 3451-3461.

Chronis, A.M., Chacko, A., Fabiano, G.A., Wymbs, B.T., \& Pelham, W.E. (2004). Enhancements to the behavioral parent training paradigm for families of children with ADHD: Review and future directions. Clinical Child and Family Psychology Review, 7(1), 1-27.

Coyne, J. C., Kessler, R. C., Tal, M., Tumbull, J., Wortman, C. B., \& Gredan., J. E. (1987). Living with a depressed person. Journal of Consulting and Clinical Psychology, 55(3), 347-352.

Cunningham, C. E., Benness, B. B., \& Siegel, L. S. (1988). Family functioning, time allocation, and parental depression in the families of normal and ADHD children. Journal of Clinical Child Psychology, 17, 169-177.

Daley, D., \& Birchwood, J. (2010). ADHD and academic performance: Why does ADHD impact on academic performance and what can be done to support ADHD children in the classroom? Child: care, health and development, 36, 455-464.

Deault, L.C. (2010). A systematic review of parenting in relation to the development of comorbidities and functional impairments in children with Attention-Deficit/Hyperactivity Disorder (ADHD). Child Psychiatry \& Human Development, 41, 168-192. 
Delle Fave, A., Fianco, A., \& Sartori, R. D. G. (2015). Psychology and relational resources in the experience of disability and caregiving. In S. Joseph (Ed.) Positive Psychology in Practice. (pp. 615-633). Haboken, NJ: Wiley.

Di Corcia , J. A. \& Tronick , E. (2011). Quotidian resilience: Exploring mechanisms that drive resilience from a perspective of everyday stress and coping. Neuroscience and Biobehavioral Reviews, 35, 1593-1602.

Du Paul, G. J., Mc Goey, K. E., Eckert, T. L., \& Van Brakle, J. (2001). Preschool children with AttentionDeficit/Hyperactivity Disorder: Impairments in behavioral, social, and school functioning. Journal of the American Academy of Child and Adolescent Psychiatry, 40, 508-515.

Durukan, I., Kara, K., Almbaideen, M., Karaman, D., \& Gül, H. (2018) Alexithymia, depression and anxiety in parents of children with neurodevelopmental disorder: Comparative study of autistic disorder, pervasive developmental disorder not otherwise specified and attention deficit-hyperactivity disorder. Pediatrics International, 60 (3): 247-253.

Edbom, T. R. N., Granlund, M., Lichtenstein, P., \& Larsson, J. (2008). ADHD symptoms related to profiles of self-esteem in a longitudinal study of twins. A person-oriented approach. Journal of Child and Adolescent Psychiatric Nursing, 21, 228-237.

Ellingsen, R., Baker, B. L., Blacher, J., \& Crnic, K. (2014). Resilient parenting of children at developmental risk across middle childhood. Research in Developmental Disabilities, 35(6), 1364-1374.

Emerson, E., McCulloch, A., Graham, H., Blacher, J., Llwellyn, G. M., \& Hatton, C. (2010). Socioeconomic circumstances and risk of psychiatric disorders among parents of children with early cognitive delay. American Journal on Intellectual and Developmental Disabilities, 115(1), 30-42.

Faraone, S. V., \& Biederman, J. (1997). Do attention deficit hyperactivity disorder and major depression share familial risk factors? Journal of Nervous and Mental Disease, 185, 533-541.

Faraone, S. V., Asherson, P., Banaschewski, T., Biederman, J., Buitelaar, J. K., Ramos-Quiroga, J. A., ... Franke, B. (2015). Attention-deficit/hyperactivity disorder. Nature Reviews Disease Primers, 1, 1-23.

Faraone, S. V., Biederman, J., \& Milberger, S. (1994). An exploratory study of ADHD among second degree relatives of ADHD children. Biological Psychiatry, 35, 398-402.

Faraone, S. V., Biederman, J., Lehman, B. K., Spencer, T., Norman, D., Seidman, L. J., .. . Tsuang, M. T. (1993). Intellectual performance and school failure in children with attention deficit hyperactivity disorder and in their siblings. Journal of Abnormal Psychology, 102(4), 616-623.

Farmer, C., Thienemann, M., Leibold, C., Kamalani, G., Sauls, B., \& Frankovich, J. (2018). Psychometric evaluation of the Caregiver Burden Inventory in children and adolescents with PANS. Journal of Pediatric Psychology, 43(7), 749-757.

Fekete, C., Tough, H., Siegrist, J., \& Brinkhof, M. W. (2017). Health impact of objective burden, subjective burden and positive aspects of caregiving: An observational study among caregivers in Switzerland. $B M J$ Open, 7(12) e017369.

Fianco, A., Sartori, R. D. G., Negri, L., Lorini, S., Valle, G., \& Delle Fave, A. (2015). The relationship between burden and well-being among caregivers of Italian people diagnosed with severe neuromotor and cognitive disorders. Research in Developmental Disabilities, 39, 43-54.

Finzi-Dottan, R., Triwitz, Y. S., Golubchik, P. (2011). Predictors of stress-related growth in parents of children with ADHD. Research in Developmental Disabilities. 32, 510-519.

Fischer, M. (1990). Parenting stress and the child with Attention Deficit Hyperactivity Disorder. Journal of Clinical Child Psychology, 19, 337-346.

Friborg, O., Barlaug, D., Martinussen, M., Rosenvinge, J. H., \& Hjemdal, O. (2005). Resilience in relation to personality and intelligence. International Journal of Methods in Psychiatric Research, 14(1), 29-42.

Friborg, O., Hjemdal, O., Rosenvinge, J. H., \& Martinussen, M. (2003). A new rating scale for adult resilience: What are the central protective resources behind healthy adjustment? International Journal of Methods in Psychiatric Research, 12, 65-67.

Friborg, O., Hjemdal, O., Rosenvinge, J. H., Martinussen, M., Aslaksen, P. M., \& Flaten, M. A. (2006). Resilience as a moderator of pain and stress. Journal of Psychosomatic Research, 61(2), 213-219.

Fridman, M., Banaschewski, T., Sikirica, V., Quintero, J., Erder, M. H., \& Chen, K. S. (2017). Factors associated with caregiver burden among pharmacotherapy-treated children/adolescents with ADHD in the caregiver perspective on pediatric ADHD survey in Europe. Neuropsychiatric Disease and Treatment. 7,13: 373-386.

Gaugler, J. E., Kane, R. L., \& Newcomer, R. (2007). Resilience and transitions from dementia caregiving. The Journal of Gerontology Series B. Psychological Science and Social Sciences, 62(1), P38-44.

Gerstein, E. D., Crnic, K. A., Blacher, J. \& Baker, B. L. (2009). Resilience and the course of daily parenting stress in families of young children with intellectual disabilities. Journal of Intellectual Disability Research 53, 981-997. 
Gönen Şentürk, S., Akyol, M., \& Küçükgüçlü, Ö. (2018). The Relationship between Caregiver Burden and Psychological Resilience in Caregivers of Individuals with Dementia. Scandinavian Journal of Caring Sciences, 11. 1223-1230.

Gohari, Z., Dehghani, F., Rajabi, G., \& Mahmoudi-Gharaei, J. (2012). Parenting self-efficacy in mothers of children with Attention Deficit Hyperactivity Disorder vs. normal children. Iranian Journal of Psychiatry, 7, 57-60.

Graungaard, A., Andersen, J., \& Skov, L. (2011). When resources get sparse: A longitudinal, qualitative study of emotions, coping and resource-creation when parenting a young child with severe disabilities. Health: An Interdisciplinary Journal for the Social Study of Health, Illness and Medicine, 15, 115-136.

Harpin, V. A. (2005). The effect of ADHD on the life of an individual, their family, and community from preschool to adult life. Archives of Disease in Childhood, 90, i2-i7.

Harrison, C., \& Sofronoff, K. (2002). ADHD and parental psychological distress: Role of demographics, child behavioral characteristics, and parental cognitions. Journal of the American Academy of Child and Adolescent Psychiatry, 41, 703-711.

Harvey, E. A. (2000). Parenting similarity and children with Attention-Deficit/Hyperactivity Disorder. Child and Family Behavior Therapy, 22, 39-53.

Heath, C. L., Curtis, D. F., Fan, W., \& McPherson, R. (2015). The association between parenting stress, parenting self-efficacy, and the clinical significance of child ADHD symptom change following Behavior Therapy. Child Psychiatry \& Human Development, 46, 118-129.

Hinkle, D. E., Wiersma, W., \& Jurs, S. G. (2003). Applied statistics for the behavioral sciences. Boston: Houghton Mifflin.

Hjemdal , O. (2007). Measuring protective Factors: The development of two resilience scales in Norway. Child and Adolescent Psychiatric Clinics in North America, 16, 303-321.

Hoza, B., Owens, J. S., Pelham, W. E., Swanson, J. M., Conners, C. K., Hinshaw, S. P., ... Kreamer, H. C. (2000). Parent cognitions as predictors of child treatment response in Attention-Deficit/Hyperactivity Disorder. Journal of Abnormal Child Psychology, 28, 569-83.

Ji, B., Sun, M., Yi, R., \& Tang, S. (2014). Multidisciplinary parent education for caregivers of children with Autism Spectrum Disorders. Archives of Psychiatric Nursing, 28, 319-326.

Jiang, Y., Gurm, M., \& Johnston, C.(2014). Child impairment and parenting self-efficacy in relation to mothers' views of ADHD treatments. Journal of Attention Disorders, 18(6), 532-541.

Johnston, C., \& Mash, E. J. (2001). Families of children with Attention-Deficit/Hyperactivity Disorder: Review and recommendations for future research. Clinical Child and Family Psychology Review, 4, 183-207.

Johnston, C., Mah, J. W. T., \& Regambal, M. (2010). Parenting cognitions and treatment beliefs as predictors of experience using behavioral parenting strategies in families of children with Attention-Deficit/Hyperactivity Disorder. Behavior Therapy, 41, 491-504.

Jones, T. L., \& Prinz, R. J. (2005). Potential roles of parental self-efficacy in parent and child adjustment: A review. Clinical Psychology Review, 25, 341-63.

Koenker, R. (1981). A note on studentizing a test for heteroscedasticity. Journal of Econometrics, 17(1), 107112.

Lane, J. B., Salter, A. R., Jones, N. E., Cutter, G., Horrigan, J., Skinner, S. A., .. Percy, A. K. (2017). Assessment of Caregiver Inventory for Rett Syndrome. Journal of Autism and Developmental Disorders, 47(4), 1102-1112.

Lange, G., Sheerin, D., Carr, A., Dooley, B., Barton, V., Marshall, D., . . Doyle, M. (2005). Family factors associated with attention deficit hyperactivity disorder and emotional disorders in children. Journal of Family Therapy, 27(1), 76-96.

Lee, Y. J., Park, H. J, \& Recchia, S. L. (2015). Embracing each other and growing together: Redefining the meaning of caregiving a child with disabilities. Journal of Child and Family Studies, 24, 3662-3675.

Lindsey, R. A., \& Barry, T. D. (2018). Protective factors against distress for caregivers of a child with Autism Spectrum Disorder. Journal of Autism and Developmental Disorders, 48(4), 1092-1107.

Lloyd, T., \& Hastings, R. P. (2009). Parental locus of control and psychological well-being in mothers of children with intellectual disability. Journal of Intellectual \& Developmental Disability,34, 104-15.

Luthar, S. S., Chicchetti , D. \& Becker, B. (2000). The construct of resilience: A critical evaluation and guidelines for future work. Child Development, 71 (3), 543-562.

Margari, F., Craig, F., Petruzzelli, M., Lamanna, A., Matera, E., \& Margari, L. (2013). Parents psychopathology of children with Attention Deficit Hyperactivity Disorder. Research in developmental disabilities, 34. 10361043.

Marvardi, M., Mattioli, P., Spazzafumo, L., Mastriforti, R., Rinaldi, P., Polidori, M. C., ... Italian Society of Gerontology and Geriatrics (2005). The caregiver burden inventory in evaluating the burden of caregivers of 
elderly demented patients: Results from a multicenter study. Aging Clinical and Experimental Research, 17, 46-53.

Mash, E. J., \& Johnston, C. (1983). Parental perceptions of child behavior problems, parenting self-esteem, and mothers' reported stress in younger and older hyperactive and normal children. Journal of Consulting and Clinical Psychology, 51, 86-99.

Masten, A. S. \& Obradovic , J. (2007). Disaster preparation and recovery: Lessons from research on resilience in human development. Ecology and Society, 13 (1), 9.

Masten, A. S., \& Wright, M. O. D. (2009). Resilience over the lifespan: Developmental perspectives on resistance, recovery, and transformation. In J. W. Reich, A. J. Zautra, \& J. S. Hall (Eds.), Handbook of adult resilience (pp. 213-237). New York, NY: Guilford Press.

Masten, A. S., Cutuli, J. J., Herbers, E., \& Reed, M. G. (2009). Resilience in development. In C. R. Snyder, \& S. J. Lopez (Eds.), Oxford Handbook of Positive Psychology (pp. 117-131). New York: Oxford University Press.

Mazzone, L., Postorino, V., Reale, L., Guarnera, M., Mannino, V., Armando, ... Vicari, S. (2013). Self-esteem evaluation in children and adolescents suffering from ADHD. Clinical practice and epidemiology in mental health, 9, 96-102.

Migerode, F., Maes, B., Buysse, A., \& Brondeel, R. (2012). Quality of life in adolescents with a disability and their parents: The mediating role of social support and resilience. Journal of Developmental and Physical Disabilities, 24, 487-503.

Modesto-Lowe, V., Chaplin, M., Godsay, V., \& Soovajian, V. (2014). Parenting teens with AttentionDeficit/Hyperactivity Disorder: Challenges and opportunities. Clinical Pediatrics, 53(10), 943-948.

Montes, G., \& Halterman, J. S. (2007). Psychological functioning and coping among mothers of children with Autism: A population-based study. Pediatrics, 119(5), e1040-e1046.

Motl, R. W., McAuley, E., Snook, E. M., \& Gliottoni, R. C. (2009). Physical activity and quality of life in multiple sclerosis: Intermediary roles of disability, fatigue, mood, pain, self-efficacy and social support. Psychology, Health \& Medicine, 14, 111-124.

Mueller, A.K., Fuermaier, A.B.M.,Koerts, J., \& Tucha, L. (2012). Stigma in Attention Deficit Hyperactivity Disorder. Attention Deficit and Hyperactivity Disorders, 4:101-114.

Murphy, K. R., \& Barkley, R. A. (1996). Parents of children with Attention Deficit Hyperactivity disorder: Psychological and attentional impairment. American Journal of Orthopsychiatry, 66, 93-102.

Neff, P. E. (2008). ADHD and Maternal Resiliency: A Cross-Cultural Examination of Canadian and American Mothers. Amherst, NY: Cambria Press.

Neff, P. E. (2010). Fathering an ADHD child: An examination of paternal well-being and social support. Sociological Inquiry, 80, 531-553.

Negri, L., Piazza, G., Sartori, R. D. G., Cocchi, M. G., \& Delle Fave, A. (2018). The Adult Carer Quality of Life questionnaire (AC-QoL): Comparison with measures of burden and well-being, and Italian validation. Disability and Rehabilitation, 1-10. doi: 10.1080/09638288.2017.1423519

Novak, M., \& Guest, C. (1989). Caregiver burden inventory. The Gerontologist, 29, 798-803.

Oelofsen, N., \& Richardson, P. (2006). Sense of coherence and parenting stress in mothers and fathers of preschool children with developmental disability. Journal of intellectual \& developmental disability, 31, 112.

Ong, A. D., Bergeman, C. S., Bisconti, T. L., \& Wallace, K. A. (2006). Psychological resilience, positive emotions, and successful adaptation to stress in later life. Journal of Personality and Social Psychology, 91(4), 730-749.

Ong, H., Vaingankar, J., Abdin, E., Sambasivam, R., Fauziana, R.,Tan, M. et al. (2018). Resilience and burden in caregivers of older adults: Moderating and mediating effects of perceived social support. BMC Psychiatry. 18- 27.Pastura, G. M., Mattos, P., \& Araújo, A. P. (2009). Academic performance in ADHD when controlled for comorbid learning disorders, family income, and parental education in Brazil. Journal of Attention Disorders, 12, 469-73.

Peer, J. W., \& Hillman, S. B. (2014). Stress and Resilience for Parents of Children With Intellectual and Developmental Disabilities: A Review of Key Factors and Recommendations for Practitioners. Journal of Policy and Practice in Intellectual Disabilities, 11(2), 92-98.Pelham, W. E. Jr, Wheeler, T., \& Chronis, A. (1998). Empirically supported psychosocial treatments for Attention Deficit Hyperactivity Disorder. Journal of Clinical Child \& Adolescent Psychology, 27(2),190-205.

Pelham, W. E. Jr. \& Fabiano, G. A. (2008). Evidence-based psychosocial treatments for AttentionDeficit/Hyperactivity Disorder. Journal of Clinical Child \& Adolescent Psychology, 37(1), 184-214.

Peveri, L. (2010). Resilienza e regolazione delle emozioni: un approccio multimodale. [Resilience and emotion regulation: A multimodal approach.] Unpublished doctoral dissertation, Milano-Bicocca University, Milano, Italy. 
Picardi, A., Gigantesco, A., Tarolla, E., Stoppioni, V., Cerbo, R., Cremonte, M., ... Nardocci, F. (2018) Parental burden and its correlates in families of children with autism spectrum disorder: A multicentre study with two comparison groups. Clinical Practice \& Epidemiology in Mental Health, 14, 143-176.

Polanczyk, G., de Lima, M. S., Horta, B. L., Biederman, J., Rohde, L. A. (2007). The worldwide prevalence of ADHD: A systematic review and metaregression analysis. American Journal of Psychiatry, 164, 942-948.

Potasznik, H., \& Nelson, G. (1984). Stress and social support: The burden experienced by the family of a mentally ill person. American Journal of Community Psychology, 12(5), 589-607.

Primack, B. A., Hendricks, K. M., Longacre, M. R., Adachi-Mejia, A. M., Weiss, J. E., Titus, L. J., ... Dalton, M. A. (2012). Parental efficacy and child behavior in a community sample of children with and without Attention-Deficit Hyperactivity Disorder (ADHD). Attention Deficit and Hyperactivity Disorders, 4,189-97.

Robertson, S. M., Zarit, S. H., Duncan, L. G., Rovine, M. J., \& Femia, E. E. (2007). Family caregivers' patterns of positive and negative affect. Family Relations, 56, 12-23.

Rogers, M. A., Wiener, J., Marton, I., \& Tannock, R. (2009). Parental involvement in children's learning: Comparing parents of children with and without Attention-Deficit/Hyperactivity Disorder (ADHD). Journal of School Psychology, 47, 167-85.

Rolland, J. S., \& Walsh, F. (2006). Facilitating family resilience with childhood illness and disability. Pediatric Opinion, 18, 1-11.

Ruiz-Robledillo, N., De Andres-Garcia, S., Perez-Blasco, J., Gonzalez-Bono, E., \& Moya-Albiol, L. (2014). Highly resilient coping entails better perceived health, high social support and low morning cortisol levels in parents of children with autism spectrum disorder. Research in Developmental Disabilities, 35, 686-695.

Rutter, M. (1987). Psychosocial resilience and protective mechanisms. American Journal of Orthopsychiatry, 57(3), 316-331.

Scahill, L., Schwabstone, M., Merikangas, K. R., Leckman, J. F., Zhang, H., \& Kasl, S. (1999). Psychosocial and clinical correlates of ADHD in a community sample of school-age children. Journal of the American Academy of Child \& Adolescent Psychiatry, 38, 976-984.

Sellmaier, C., Leo, M. C., Brennan, E. M., Kendall, J., \& Houck, G. M. (2016). Finding fit between work and family responsibilities when caring for children with ADHD diagnoses. Journal of Child and Family Studies, 25(12), 3684-3693.

Shelton, T. L., Barkley, R. A., Crosswait, C., Moorehouse, M., Fletcher, K., Barrett, S., ... Metevia, L. (1998). Psychiatric and psychological morbidity as a function of adaptive disability in preschool children with aggressive and hyperactive impulsive inattentive behavior. Journal of Abnormal Child Psychology, 26, 475494.

Shur-Fen Gau, S. (2007) Parental and family factors for attention-deficit hyperactivity disorder in Taiwanese children., Australian and New Zealand Journal of Psychiatry, 41(:8), 688-696.

Sobol, M. P., Ashbourne, D. T., Earn, B. M., \& Cunningham, C. E. (1989). Parents' attributions for achieving compliance from attention deficit disordered children. Journal of Abnormal Child Psychology, 17, 359-369.

Song, J., Mailick, M. R., Ryff, C. D., Coe, C. L., Greenberg, J. S., \& Hong, J. (2014). Allostatic load in parents of children with developmental disorders: Moderating influence of positive affect. Journal of Health Psychology, 19, 262-272.

Tarver, J., Daley, D., \& Sayal, K. (2015). Beyond symptom control for Attention-Deficit Hyperactivity Disorder (ADHD): What can parents do to improve outcomes? Child: Care, Health and Development, 41, 1-14.

Theule, J., Wiener, J., Rogers, M. A., \& Marton, I. (2011). Predicting parenting stress in families of children with ADHD: Parent and contextual factors. Journal of Child and Family Studies, 20, 640-647.

Theule, J., Wiener, J., Tannock, R., \& Jenkins, J. M. (2013). Parenting stress in families of children with ADHD: A meta-analysis. Journal of Emotional and Behavioral Disorders, 21, 3-17.

Thomas, R., Sanders, S., Doust, J., Beller, E., Glasziou, P. (2015) Prevalence of Attention-Deficit/ Hyperactivity Disorder: A systematic review and meta-analysis. Pediatrics, 135(4), 1-8.

Vagharseyyedin, S.A., \& Molazem, Z. (2013). Burden, resilience, and happiness in family caregivers of spinal cord injured patients. Middle east journal of psychiatry and Alzheimers, 4 (1), 29-35.

Vitanza, S. A., \& Guarnaccia, C. A. (1999). A model of psychological distress for mothers of children with Attention-Deficit Hyperactivity Disorder. Journal of Child and Family Studies, 8, 27-45.

Walerius, D. M., Fogleman, N. D., \& Rosen, P. J. (2016). The role of ADHD and negative emotional lability in predicting changes in parenting daily hassles. Journal of Child and Family Studies, 25, 2279-2291.

Ware, J. E. Jr., \& Sherbourne, C. D.(1992). The MOS 36-item short-form health survey (SF-36). I. Conceptual framework and item selection. Medical Care, 30, 473-83.

Wehmeier, P. M., Schacht, A., \& Barkley, R. A. (2010). Social and emotional impairment in children and adolescents with ADHD and the impact on quality of life. Journal of Adolescent Health, 46, 209-217. 
Weiss, M. (2015). Functional impairment in ADHD. In L.A. Adler, T.J. Spencer, \& T.E. Wilens (Eds.), Attention-Deficit Hyperactivity Disorder in Adults and children. (pp.42-52). Cambridge, England: Cambridge University Press.

Weiss J. A., Robinson S., Fung S., Tint A., Chalmers P., Lunsky Y. (2013). Family hardiness, social support, and self-efficacy in mothers of individuals with autism spectrum disorders. Research in Autism Spectrum Disorders 7, 1310-1317.

Werner, E. E. (2000). Protective factors and individual resilience. In J. P. Shonkoff \& S. J. Meisels (Eds.), Handbook of Early Childhood Intervention. (pp. 115-132). New York, NY, US: Cambridge University Press.

Willcutt, E. G. (2012). The prevalence of DSM-IV Attention-deficit/hyperactivity disorder: A meta-analytic review. Neurotherapeutics, 9, 490-499.

Zarit, S.H., Reever, K.E., Bach-Peterson, J. (1980). Relatives of the impaired elderly: Correlates of feelings of burden. Gerontologist, 20 (6): 649-655.

Zautra, A. J., \& Reich, J. W. (2012). Resilience: The meanings, methods, and measures of a fundamental characteristic of human adaptation. In The Oxford handbook of stress, health, and coping. Oxford University Press.

Zwi, M., Jones, H., Thorgaard, C., York, A., \& Dennis, J. A. (2009). Parent training interventions for attention deficit hyperactivity disorder. The Cochrane database of systematic reviews, (3), CD003018. 


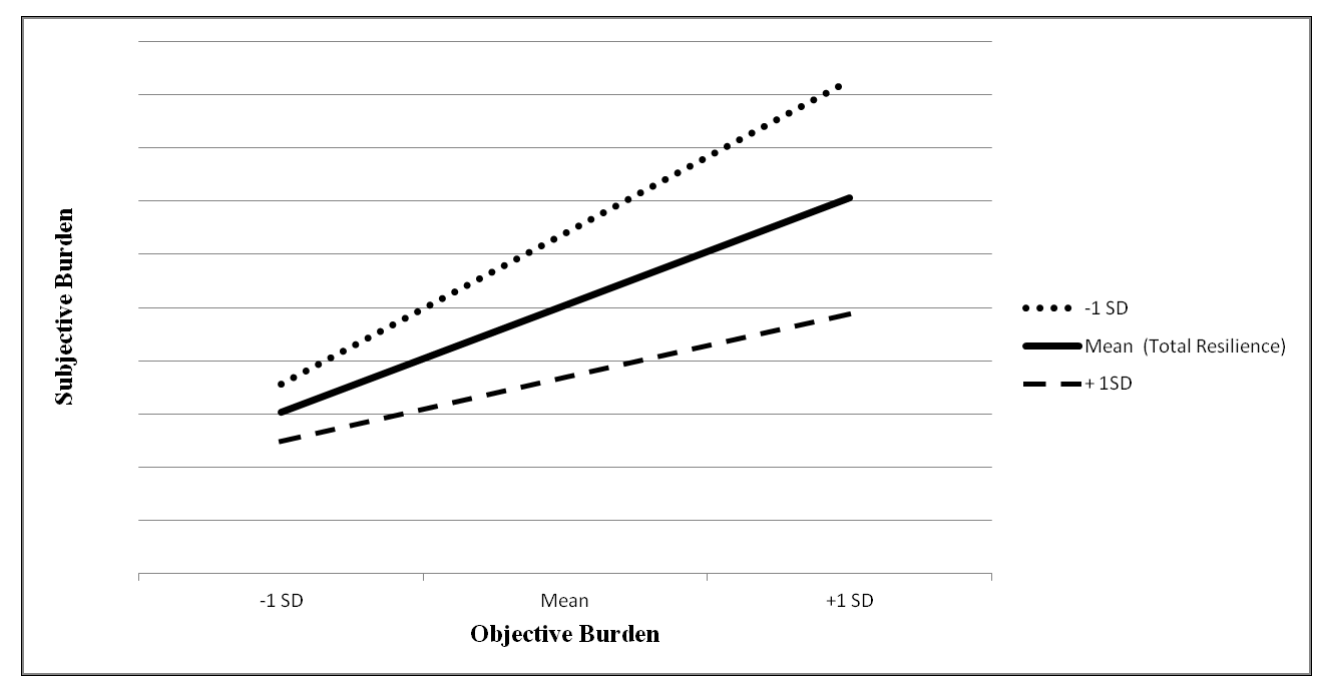

Figure 1. Simple slopes predicting Subjective Burden from Objective Burden at three levels of Total Resilience

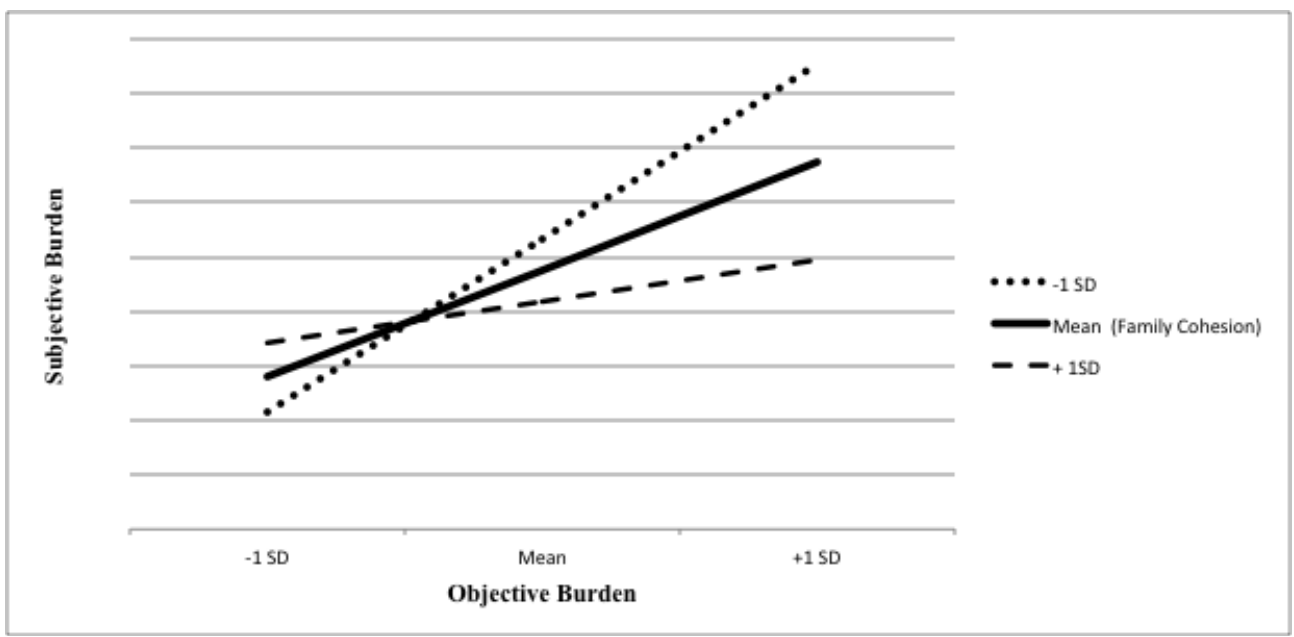

Figure 2. Simple slopes predicting Subjective Burden from Objective Burden at three levels of Family Cohesion. 


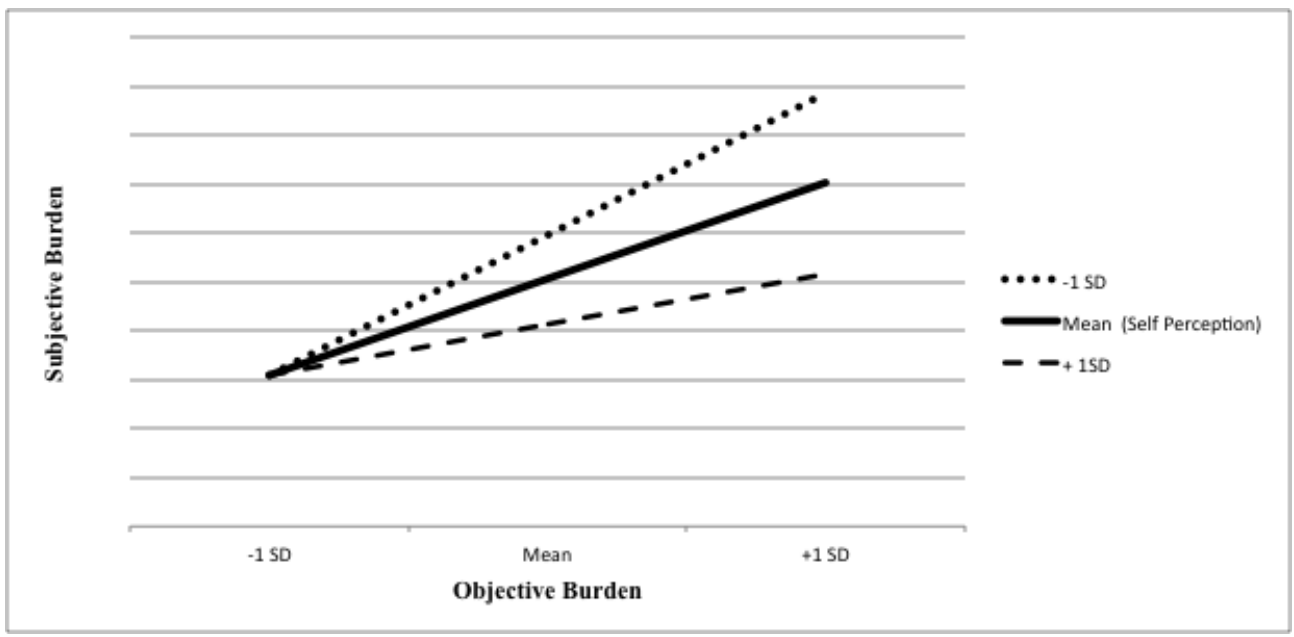

Figure 3. Simple slopes predicting Subjective Burden from Objective Burden at three levels of Self Perception. 
Table 1. Descriptive statistics and correlation indices among study measures

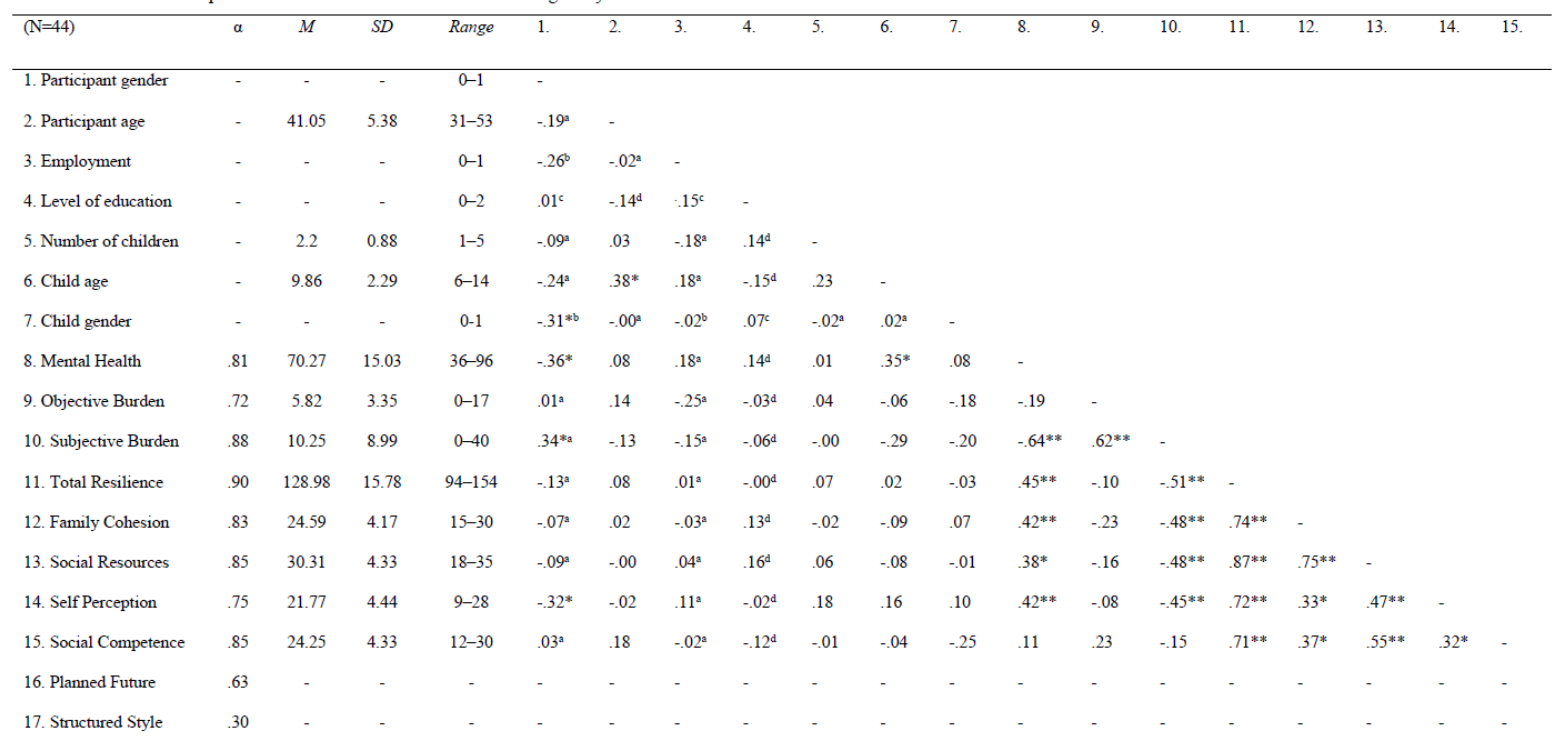

Note. Participant gender: $0=$ male, $1=$ female; Employment: $0=$ not employed, $1=$ employed; Level of education: $0=$ middle school diploma, 1 =high school diploma, $2=$ college degree; Child gender: $0=$ male, $1=$ female; $\alpha=$ Cronbach alpha reliability index; $\mathrm{M}=$ mean; $\mathrm{SD}=$ standard deviation; ${ }^{\mathrm{a}}=$ point biserial correlation; ${ }^{\mathrm{b}}=$ tetrachoric correlation; ${ }^{\mathrm{c}=\text { =rank }}$ biserial correlation; ${ }^{\mathrm{d}=\mathrm{Spearman}}$ rank correlation; Where not otherwise indicated, Pearson correlation indices are reported; ${ }^{*} p<.05 ; * * p<.01$ 
Table 2. Moderation analysis (Total Resilience)

\begin{tabular}{lcccccc}
\hline $\mathrm{N}=44$ & & & \multicolumn{3}{c}{ Subjective Burden (SB) } \\
\hline Variable & $\mathrm{B}$ & $S E \mathrm{~B}$ & $\beta$ & $t$ & $\Delta R^{2}$ & $p$ \\
\hline Step l & & & & & .33 & $<.001$ \\
Gender & 4.12 & 1.98 & .18 & 2.09 & -04 \\
Mental Health & -0.21 & 0.06 & -.35 & -3.64 & .001 \\
Objective Burden (OB) & 1.40 & 0.22 & .52 & 6.40 & -3.15 & .001 \\
Total Resilience & -0.160 & 0.05 & -.28 & & .003 \\
Step 2 & & & & & .03 \\
Gender & 3.90 & 1.88 & .17 & 2.08 & .04 \\
Mental Health & -0.21 & 0.05 & -.36 & -3.88 & & $<.001$ \\
Objective Burden (OB) & 1.21 & 0.22 & .45 & 5.36 & & $<.001$ \\
Total Resilience & -0.17 & 0.05 & -.30 & -3.54 & & .001 \\
OB x Total Resilience & -0.03 & 0.01 & -0.18 & -2.23 & & .03 \\
\hline
\end{tabular}


Table 3. Moderation analysis (Family Cohesion)

\begin{tabular}{lllllll}
\hline $\mathrm{N}=43$ & & \multicolumn{5}{c}{ Subjective Burden (SB) } \\
\hline Variable & $\mathrm{B}$ & $\mathrm{SE} \mathrm{B}$ & $\beta$ & $t$ & $\Delta R^{2}$ & $p$ \\
\hline Step l & & & & & .29 & $<.001$ \\
Gender & 4.17 & 2.16 & .18 & 1.93 & .06 \\
Mental Health & -0.24 & 0.06 & -.41 & -3.85 & $<.001$ \\
Objective Burden & 1.34 & 0.26 & .48 & 5.22 & $<.001$ \\
Family Cohesion & -.38 & .24 & -.17 & -1.62 & .12 \\
Step 2 & & & & & .04 & .01 \\
Gender & 3.38 & 2.04 & -.15 & 1.65 & .11 \\
Mental Health & -0.25 & 0.06 & -.42 & -4.28 & $<.001$ \\
Objective Burden (OB) & 1.21 & 0.25 & .43 & 4.91 & .001 \\
Family Cohesion (FC) & -0.29 & 0.22 & -.13 & -1.32 & .20 \\
OB x FC & -0.19 & 0.07 & -.22 & -2.56 & .01 \\
\hline
\end{tabular}


Table 4. Moderation analysis (Self Perception)

\begin{tabular}{lllllll}
\hline $\mathrm{N}=$ 44 & & & \multicolumn{4}{c}{ Subjective Burden (SB) } \\
\hline Variable & $\mathrm{B}$ & $\mathrm{SE} \mathrm{B}$ & $\beta$ & $t$ & $\Delta R^{2}$ & $p$ \\
\hline Step l & & & & & .29 & $<.001$ \\
Gender & 3.05 & 2.15 & .132 & 1.42 & .16 \\
Mental Health & -.25 & 0.06 & -.41 & -4.17 & $<.001$ \\
Objective Burden (OB) & 1.40 & 0.23 & .52 & 5.99 & $<$ & $<.001$ \\
Self Perception (SP) & -0.38 & 0.19 & -.19 & -1.97 & .06 \\
Step 2 & & & & & .03 & .047 \\
Gender & 2.58 & 2.08 & .11 & 1.24 & .22 \\
Mental Health & -0.26 & 0.06 & -.44 & -4.57 & $<.001$ \\
Objective Burden (OB) & 1.22 & 0.24 & .45 & 5.04 & $<.001$ \\
Self Perception (SP) & -0.38 & 0.19 & -.19 & -2.02 & .05 \\
OB x SP & -0.12 & 0.06 & -.18 & -2.05 & .047 \\
\hline
\end{tabular}

